PAPER

\title{
Inappropriate emergency management of status epilepticus in children contributes to need for intensive care
}

\author{
R F M Chin, L Verhulst, B G R Neville, M J Peters, R C Scott
}

J Neurol Neurosurg Psychiatry 2004;75:1584-1588. doi: 10.1136/jnnp.2003.032797

See end of article for authors' affiliations

....................

Correspondence to: Dr R F M Chin, Neurosciences Unit, Institute of Child Health University College London, and Great Ormond Street Hospital for Children NHS Trust, London WCIN 1EH, UK; r.chin@ich.ucl.ac.uk

Received

19 November 2003

In revised form

22 January 2004

Accepted 2 February 2004
Objectives: To characterise the clinical features, emergency pre-paediatric intensive care (PIC) treatment, and course of status epilepticus (SE) in children admitted to PIC. This may provide insight into reasons for admission to PIC and provide a framework for the development of strategies that decrease the requirement for intensive care.

Design: Cross sectional, retrospective study.

Setting: A tertiary paediatric institution's intensive care unit.

Participants: The admission database and all discharge summaries of each admission to a tertiary paediatric institution's PIC over a three year period were searched for children aged between 29 days and 15 years with a diagnosis of SE or related diagnoses. The case notes of potential cases of SE were systematically reviewed, and clinical and demographic data extracted using a standard data collection form.

Results: Most children with SE admitted to PIC are aged less than 5 years, male to female ratio 1:1, and most (77\%) will have had no previous episodes of SE. Prolonged febrile convulsions, SE related to central nervous system infection, and SE associated with epilepsy occur in similar proportions. Contrary to the Advanced Paediatric Life Support guidelines many children admitted to PIC for SE receive over two doses, or inadequate doses, of benzodiazepine. There is a risk of respiratory depression following administration of over two doses of benzodiazepine $\left(\chi^{2}=3.4, p=0.066\right)$. Children with SE admitted to PIC who had prehospital emergency treatment are more likely to receive over two doses of benzodiazepines $\left(\chi^{2}=11.5\right.$, $p=0.001)$, and to subsequently develop respiratory insufficiency $\left(\chi^{2}=6.2, p=0.01\right)$. Mortality is low. Further study is required to determine the morbidity associated with SE in childhood requiring intensive care.

Conclusions: As the risk of respiratory depression is greater with more than two doses of benzodiazepines, clinicians should not disregard prehospital treatment of SE. As pre-PIC treatment of $\mathrm{SE}$ is inadequate in many cases, appropriate audit and modifications of standard guidelines are required.
S tatus epilepticus (SE) is the most common neurological emergency in childhood. ${ }^{2}$ Cases referred to a tertiary centre may reflect the severe end of the spectrum of this condition, with those requiring admission to paediatric intensive care (PIC) being the most severely affected. Thus, data from admissions to PIC for SE may provide some insight into determinants of severity of SE and facilitate the development of appropriate strategies to reduce severity. Despite this, studies on admission to PIC for SE are rare. In the only published study, 147 children were admitted to PIC for SE, over a 10 year period. ${ }^{3}$ Most cases were either prolonged febrile convulsions (PFCs) or related to an acute neurological insult. Case fatality during hospitalisation was $6 \%$ and neurological sequelae ranging from minor impairment to persistent vegetative states were identified in about a third of children at discharge. ${ }^{3}$ Thus, data from that, and other studies, suggest that SE is associated with significant morbidity and mortality. ${ }^{4-6}$

Longer duration of seizures is associated with increased risk of morbidity and mortality. ${ }^{57}$ Delayed treatment may increase the frequency of SE. ${ }^{8}$ Therefore, early seizure termination is paramount and is reflected in guidelines for treatment of SE. ${ }^{9-12}$ In the United Kingdom (UK), the Advanced Paediatric Life Support (APLS) guideline for the management of SE is a widely accepted standard for treatment. APLS was developed and implemented in the UK in 1993 to improve the general emergency care of children. It was developed by a number paediatricians, paediatric surgeons, anaesthetists, and emergency physicians from across the UK, and is widely taught to doctors, nurses, and paramedics throughout the UK.

This study aims to:

- Characterise the clinical features of SE requiring admission to PIC

- Compare the emergency pre-PIC treatment of SE to the APLS guideline

- Characterise the course of SE in children admitted to PIC.

\section{METHODS}

Great Ormond Street Hospital for Children NHS Trust $(\mathrm{GOSH})$, is a tertiary paediatric institution in the UK. The study was approved by the GOSH and Institute of Child Health Research Ethics Committee. The diagnoses and demographics for all patients admitted to GOSH's PIC are documented in an admission database. Survival outcome of all admissions is also included. The admission database and discharge summaries of admissions during the period 1 April 1998 to 31 March 2001 were searched. All potential cases of SE were identified using the terms: status, epilep*, fit*, seizure*, and convuls ${ }^{*}$, where * indicates that any combination of letters may end the word. All such admissions of subjects aged between 29 days and 15 years were reviewed.

Abbreviations: AED, antiepileptic drug; APLS, Advanced Paediatric Life Support; CNS, central nervous system; PFC, prolonged febrile convulsion; PIC, paediatric intensive care; SE, status epilepticus. 
The case notes of these potential cases of SE were systematically reviewed. Episodes of non-convulsive SE were excluded. Cases with insufficient history or documentation to meet the definition of SE were excluded. Clinical and demographic data were extracted using a standard data collection form.

SE was defined as a seizure or series of seizures without recovery of consciousness between seizures lasting at least 30 minutes. ${ }^{13}$ Seizure type and aetiology were classified independently by two researchers. Disagreements on classifications were resolved by consensus or by third party adjudication. SE seizure types were categorised as generalised from onset, focal with secondary generalisation, or focal. ${ }^{14} \mathrm{SE}$ aetiologies were classified as PFC, acute symptomatic, acute on remote symptomatic, remote symptomatic, idiopathic epilepsy related, cryptogenic epilepsy related, or unclassified (see table 1 for further details).

The pre-PIC emergency management was compared to the APLS guidelines current during the study period (that is, the second and third editions). ${ }^{10}{ }^{11}$ Both guidelines recommend either lorazepam (administered intravenously) or diazepam (administered intravenously/rectally) as the first line drug and paraldehyde (administered rectally) as the second line drug (see fig 1 for further details on the APLS guidelines). The appropriate dose was defined as a mean of the recommended doses. Thus, the appropriate dose for lorazepam was $0.1 \mathrm{mg} / \mathrm{kg}$, and for diazepam $0.45 \mathrm{mg} / \mathrm{kg}$. If the administered dose was outside $80 \%-120 \%$ of these doses, it was considered to be inappropriately low or high. The appropriate dose of rectal paraldehyde was determined as above and was $0.3 \mathrm{ml} / \mathrm{kg}$. If the administered dose was less than $50 \%$ or greater than $150 \%$ of the appropriate dose, it was considered to be low or high.

\section{STATISTICS}

Data were entered and validated into Microsoft Access 97. Statistical testing was conducted in SPSS version 10 (SPSS Inc, Chicago, IL, USA). Kruskal-Wallis ANOVA was used to

\begin{tabular}{|c|c|}
\hline Aetiology of SE & Definition \\
\hline $\begin{array}{l}\text { Prolonged febrile } \\
\text { convulsion }\end{array}$ & $\begin{array}{l}\text { SE during a febrile (temperature above } 38^{\circ} \mathrm{C} \text { ) illness } \\
\text { in a previously neurologically normal child aged } \\
\text { between } 6 \text { months and five years, and in the absence } \\
\text { of defined central nervous system (CNS) infection. }\end{array}$ \\
\hline $\begin{array}{l}\text { Acute } \\
\text { symptomatic }\end{array}$ & $\begin{array}{l}\text { SE in a previously neurologically normal child, within } \\
\text { a week of an identified acute neurological insult } \\
\text { including head trauma, CNS infection, } \\
\text { encephalopathy, cerebrovascular disease, and } \\
\text { metabolic or toxic derangements. }\end{array}$ \\
\hline $\begin{array}{l}\text { Remote } \\
\text { symptomatic }\end{array}$ & $\begin{array}{l}\text { SE in the absence of an identified acute insult but with } \\
\text { a history of a CNS insult more than } 1 \text { week before. }\end{array}$ \\
\hline $\begin{array}{l}\text { Acute on remote } \\
\text { symptomatic }\end{array}$ & $\begin{array}{l}\text { SE that occurred within a week of an acute } \\
\text { neurological insult or febrile illness and occurred in a } \\
\text { child with a history of previous neurological } \\
\text { abnormality. This category included children with } \\
\text { cerebral palsy with a febrile illness not of CNS origin, } \\
\text { and children with obstructed ventriculo-peritoneal } \\
\text { shunts for posthaemorrhagic hydrocephalus. }\end{array}$ \\
\hline $\begin{array}{l}\text { Idiopathic } \\
\text { epilepsy related }\end{array}$ & $\begin{array}{l}\text { SE that is not symptomatic (see above) and occurred } \\
\text { in subjects with a prior diagnosis of idiopathic } \\
\text { epilepsy or when the episode of SE is the second } \\
\text { unprovoked seizure that has led to a diagnosis of } \\
\text { idiopathic epilepsy. }\end{array}$ \\
\hline $\begin{array}{l}\text { Cryptogenic } \\
\text { epilepsy related }\end{array}$ & $\begin{array}{l}\text { SE that is not symptomatic (see above) and occurred } \\
\text { in subjects with a prior diagnosis of cryptogenic } \\
\text { epilepsy or when the episode of SE is the second } \\
\text { unprovoked seizure that has led to a diagnosis of } \\
\text { cryptogenic epilepsy. }\end{array}$ \\
\hline Unclassified & SE that could not be classified into any other group. \\
\hline
\end{tabular}

investigate relations between the aetiology of SE with age, aetiology of SE with duration of SE, and aetiology of SE with duration of ventilation. $\chi^{2}$ testing was carried out to examine relations between prehospital treatment and respiratory depression after seizure termination, prehospital treatment and the number of doses of benzodiazepine, and number of doses of benzodiazepine and respiratory depression after seizure termination.

\section{RESULTS}

\section{Clinical features}

Of 2285 PIC admissions, 212 potential episodes of SE were identified. Of these, 98 (4\% of all admissions) were confirmed episodes of SE. These 98 episodes occurred in 91 patients (median age 2.2 years, range $0.1-12.1$ years; male:female ratio 1:1). Most children were under 5 years of age (86\%) and $77 \%$ had incident episodes of SE. In $44 \%$ of episodes, intubation and ventilation were necessary in order to give medication required to terminate SE, whereas in 56\% of episodes, intubation and ventilation were necessary for respiratory insufficiency following successful termination of clinically recognised seizure activity.

Similar proportions of SE occurred in children who had been previously neurologically normal compared with those with pre-existing neurological disorders (see fig 2). There is no difference in the average age of children when compared according to aetiology $\left(\chi^{2}=5.2, \mathrm{df}=4, \mathrm{p}=0.27\right.$; see fig 3$)$. Most children with acute symptomatic SE had a CNS infection (see table 2). In children with idiopathic and cryptogenic epilepsy related SE, only three (12.5\%) had antiepileptic drug (AED) levels on admission. The level was within the normal range in all three. Onset of SE was focal in $38 \%$ of children but only $7 \%$ of episodes remained focal. The mean duration of SE was 90 minutes (range 30-435 minutes), and was independent of aetiology $\left(\chi^{2}=1.5\right.$, $\mathrm{p}=0.9)$.

\section{Emergency pre-PIC treatment of status epilepticus}

Forty eight children did not receive prehospital emergency AEDs. In this group of children, the median interval between seizure onset and administration of the first AED in accident and emergency (A\&E) was 35 minutes $(n=29$, range $10-$ 155 minutes) and the median interval between arrival in A\&E and seizure termination was 50 minutes $(n=27$, range 10-105 minutes).

When the overall emergency pre-PIC treatment (prehospital and hospital) was assessed, diazepam or lorazepam was the most commonly administered first line AED but the dose was frequently lower than that recommended. Of 90 episodes that required second line AED, paraldehyde was administered in half of episodes. In these, the dose was appropriate in $49 \%$ (see table 3 ).

There is weak evidence that the risk of respiratory insufficiency following seizure termination is related to the number of doses of benzodiazepine $\left(\chi^{2}=3.4, p=0.066\right)$ (see table 4). However children who had prehospital treatment were more likely to receive more than two doses of benzodiazepine $\left(\chi^{2}=11.5, p=0.001\right)$ and those that had prehospital treatment were also more likely to have respiratory depression $\left(\chi^{2}=6.2, \mathrm{p}=0.01\right)$.

\section{PIC course of SE}

The median duration of ventilatory support was 15 hours ( $\mathrm{n}=86$, range $2-168$ hours) and was independent of aetiology $\left(\chi^{2}=7.9, p=0.16\right)$. Median length of stay on PIC was one day (range $1-13$ days). Five children $(5 \%$ of confirmed cases of SE) died. Two had acute bacterial meningitis, and one each had acute hepatic failure, a brain tumour, and a neurodegenerative disease. 


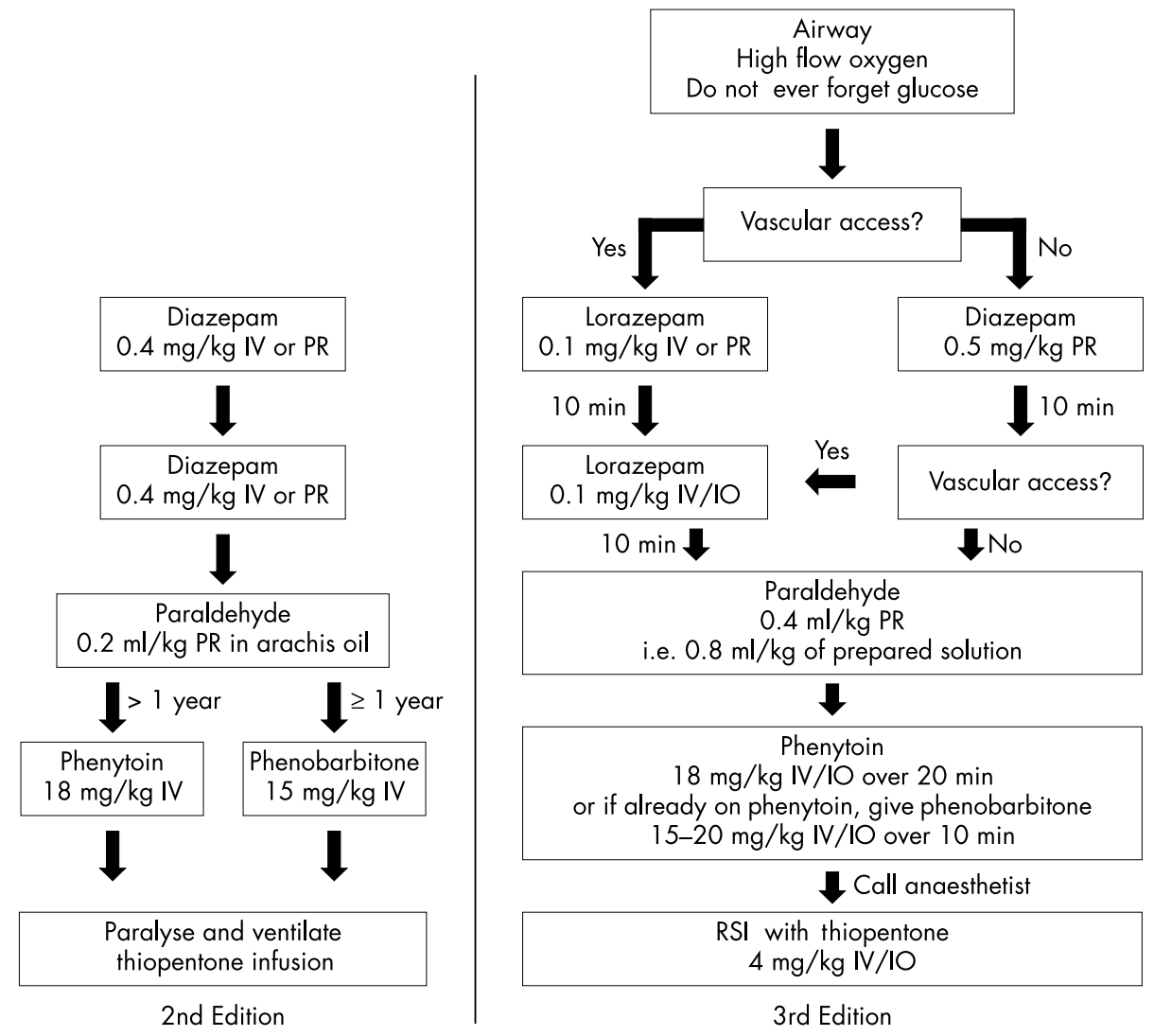

Figure 1 APLS algorithms for treatment of convulsive status epilepticus.

2nd Edition

3rd Edition

\section{DISCUSSION}

The purpose of the current study was to characterise a population of children requiring admission to PIC within the context of an episode of SE to provide a framework for strategies that reduce requirement for admission to PIC. The need for intensive care management of SE may be related to severity of SE, and there may be particular clinical

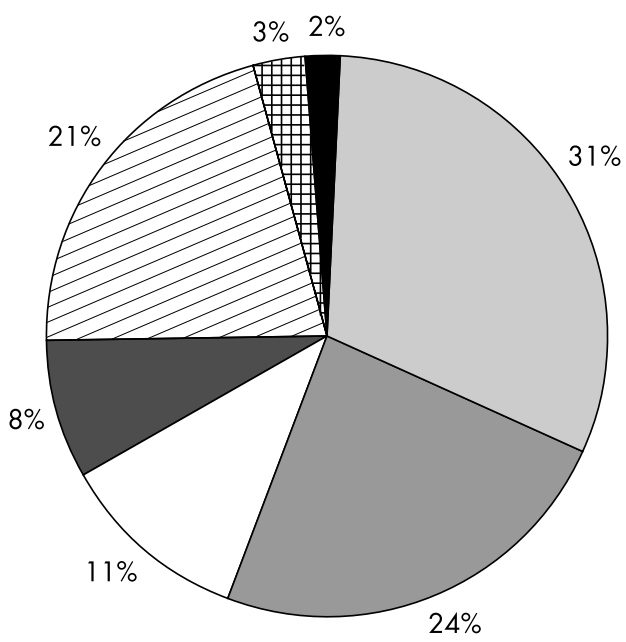

PFC

Acute on remote

Unclassified
Acute

Idiopathic epilepsy related
Remote

$\boxplus$ Cryptogenic epilepsy related
Figure 2 Aetiology of status epilepticus (SE) in children admitted to paediatric intensive care. Similar proportions of SE occurred in children who had been previously neurologically normal and those with preexisting neurological disorders, including epilepsy. characteristics of such cases that are distinct from those in cases of SE in the general population. Admissions to PIC for SE may also be due to inadequate pre-PIC emergency treatment.

The clinical features of the population of children admitted to PIC with SE from the current series can be compared with data from the general childhood population. Any observations will need to be confirmed in prospective, population

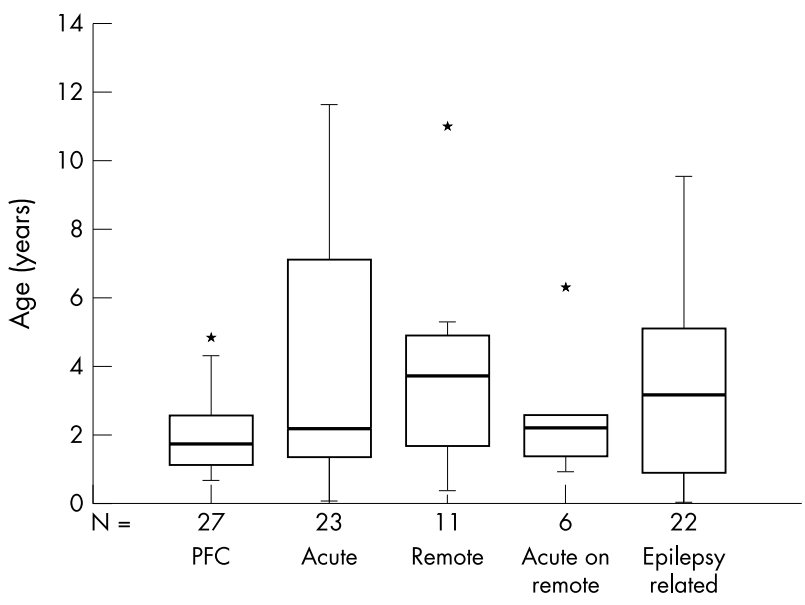

Aetiology of status epilepticus

Figure 3 Aetiology of status epilepticus according to age. The box indicates lower and upper quartiles, the central line is the median, and the points at the end of the "whiskers" represent the 2.5\% and $97.5 \%$ values of the range. An asterisk represents an outlier. There is no difference in the average values between aetiologies $\left(\chi^{2}=5.2, \mathrm{df}=4\right.$, $p=0.27)$. 
Table 2 Aetiology of acute symptomatic status epilepticus. Most cases caused by a central nervous system infection

\begin{tabular}{lll}
\hline $\begin{array}{l}\text { Aetiology of acute } \\
\text { symptomatic SE }\end{array}$ & $\begin{array}{l}\text { Number of } \\
\text { cases }\end{array}$ & $\begin{array}{l}\text { Proportion of acute } \\
\text { symptomatic SE (\%) }\end{array}$ \\
\hline CNS infection & 18 & 75 \\
Hyponatraemia & 2 & 8 \\
Following hypoxic episode & 2 & 8 \\
Generalised sepsis & 1 & 4 \\
Subdural haemorrhage & 1 & 4 \\
All & 24 & 99 \\
\hline
\end{tabular}

based studies, such as the ongoing North London convulsive STatus EPilepticus in childhood Surveillance Study (NLSTEPSS) (Chin et al, proceedings of the Annual Meeting of the American Epilepsy Society, 2003). Aside from differences in aetiology of SE, the clinical characteristics of the episodes of SE in the current series and those from population based studies ${ }^{2}{ }^{15} 16$ are very similar. Our data show similar age and sex distributions, and case fatality compared with population based studies. ${ }^{2}{ }^{15}{ }^{16}$ In the current series, a lower proportion of children were previously neurologically normal and a higher proportion of episodes were epilepsy related $(25 \% v 5-13 \%) .{ }^{2}{ }^{15}{ }^{16}$ It is possible that low AED levels in children with epilepsy related SE may contribute towards the development of SE but we were unable to determine that frequency in the current study. Within the classification of aetiologies, the designation "acute on remote symptomatic $\mathrm{SE}^{\prime \prime}$ was included in order to distinguish that group of children with previous neurological problems with fever and illness related seizures, from those who were previously neurologically normal. Such a distinction is important in order to separate the syndrome of PFC which has low morbidity and mortality. ${ }^{6}{ }^{17}$ It is not always possible to determine aetiology at the onset of SE, therefore it is unlikely that it will be possible to predict which children will require admission to PIC at the time of first medical intervention. It is, however, still possible that those children admitted to PIC with SE reflect the most severe cases within each aetiology and there may still be significant morbidity associated with such cases compared with the general population.

In comparison to the Canadian PIC study, ${ }^{3}$ a greater proportion of children were admitted to our PIC for respiratory insufficiency following seizure termination $(2.3 \% \vee 0.1 \%)$. Compared to a prospective study of children presenting to A\&E with seizures, our study reports a similar proportion of children requiring ventilation for respiratory depression associated with administration of benzodiazepines $(64 \% v 57 \%) .{ }^{18}$ The association of more than two doses of benzodiazepine with respiratory depression has been noted previously. ${ }^{19}$ Our data, which show a strong association between prehospital treatment and the administration of more than two doses of benzodiazepine, and between prehospital treatment and the risk of respiratory depression, support the hypothesis that physicians who disregard prehospital treatment may give more doses of benzodiazepine than those who do take prehospital treatment into account. This may be due to a lack of specificity of the entry point into the treatment algorithm of the APLS guideline. The issue becomes more ambiguous because the British Paediatric Neurology Association guideline for treatment of SE recommends that prehospital treatment should be ignored ${ }^{20}$ which, on the basis of the current data, may increase the need for admission to intensive care. Thus, the entry point into the guidelines for the management of SE needs to be clarified.
Table 3 Emergency pre-PIC treatment of status epilepticus

\begin{tabular}{|c|c|c|}
\hline $\begin{array}{l}\text { Emergency AED } \\
\text { treatment }\end{array}$ & $\begin{array}{l}\text { Prehospital } \\
(\%)\end{array}$ & $\begin{array}{l}\text { Overall (prehospital } \\
\text { and hospital) (\%) }\end{array}$ \\
\hline \multicolumn{3}{|l|}{ First line AED $(n=98)$} \\
\hline Treatment given & 49 & 100 \\
\hline Diazepam/lorazepam & 100 & 94 \\
\hline Dose low & 55 & 30 \\
\hline Dose appropriate & 30 & 55 \\
\hline Dose high & 5 & 3 \\
\hline Dose unknown & 0 & 12 \\
\hline Other & 0 & 6 \\
\hline No treatment & 51 & 0 \\
\hline \multicolumn{3}{|l|}{ Second line AED $(n=90)$} \\
\hline Paraldehyde & - & 50 \\
\hline Dose low & - & 16 \\
\hline Dose appropriate & - & 49 \\
\hline Dose high & - & 30 \\
\hline Dose unknown & - & 5 \\
\hline Phenytoin & - & 49 \\
\hline Dose low & - & 2 \\
\hline Dose appropriate & - & 92 \\
\hline Dose high & - & 4 \\
\hline Dose unknown & - & 2 \\
\hline Phenobarbitone & - & 1 \\
\hline Dose low & - & 0 \\
\hline Dose appropriate & - & 100 \\
\hline Dose high & - & 0 \\
\hline Dose unknown & - & 0 \\
\hline
\end{tabular}

The number of doses of benzodiazepine is not the only concern relating to the emergency treatment of SE. There are treatment delays, poor adherence to recommended doses and choice of second line emergency AED. The data from our series suggest that only one in every six children with SE admitted to PIC is appropriately treated before arrival in A\&E. When the overall emergency pre-PIC treatment is assessed, the doses of APLS recommended first and second line drugs are commonly low and the recommended second line drug, paraldehyde, is frequently omitted. Of those who did not receive rectal paraldehyde, all except one received intravenous phenytoin which, although not in the APLS guideline as a second line drug, is widely considered to be an appropriate second line agent. ${ }^{21}$ To our knowledge, there is no evidence that either is superior to the other as a second line drug $^{18}$ and in many parts of the world, rectal paraldehyde is much less used than intravenous phenytoin. Should a seizure continue for longer than 40 minutes after the initiation of treatment, the APLS guideline suggests induction of anaesthesia with thiopentone and endotracheal intubation and

Table 4 Relation between number of administered doses of benzodiazepine and respiratory depression after seizure termination.

\begin{tabular}{llll}
\hline & \multicolumn{2}{l}{ Respiratory insufficiency } & \\
\cline { 2 - 3 } Doses of benzodiazepine & No & Yes & Total \\
\hline \multirow{2}{*}{$\leqslant 2$} & 21 & 17 & 38 \\
Total & 19 & 34 & 53 \\
& 40 & 51 & 91 \\
\hline
\end{tabular}

There is weak evidence that the risk of respiratory insufficiency following seizure termination is related to the number of doses of benzodiazepine. $\left(\chi^{2}=3.4, p=0.066\right)$. Approximately $58 \%$ of episodes of SE received more than two doses of benzodiazepine 
ventilation. In A\&E, medical teams managing children with SE are adhering to this 40 minutes time line, as the observed interval between arrival to hospital and seizure termination is similar. The observed duration of SE of 90 minutes is enough to increase the potential morbidity and mortality associated with SE. ${ }^{722}$

In order to limit seizure duration, strategies to improve prehospital management will need to be considered. The use of intravenous agents is limited by the difficulty in gaining intravenous access in children, especially in those aged under 5 years. Rectal preparations, as are currently used, are limited by concerns over social unacceptability or inconvenience of administering rectal drug. Recent studies on benzodiazepines by the buccal $^{23}{ }^{24}$ or nasal ${ }^{25}$ route have reported similar efficacy to rectal diazepam without increased risk of adverse effects. Thus, there may be alternative medications that are easier, and more socially acceptable to administer. This may result in improvement in the number of children successfully treated in the prehospital setting and thereby reduce the number of children requiring intensive care treatment for SE.

\section{CONCLUSIONS}

Early initiation of treatment of SE is important to reduce its associated morbidity and mortality. Thus, it is reasonable that emergency treatment of SE should be started in the prehospital setting. As the administration of more than two doses of a benzodiazepine is associated with an increased risk of respiratory depression, then prehospital treatment should be taken into account during further treatment. Our results would indicate that guidelines for the management of SE may need to be revised to take into account the above findings, and highlight the need for appropriate audit.

\section{ACKNOWLEDGEMENTS}

Rod Scott is supported by the Wellcome Trust. Research at the Institute of Child Health and Great Ormond Street Hospital for Children NHS Trust benefits from R\&D funding received from the NHS Executive.

\section{Authors' affiliations}

R F M Chin, B G R Neville, R C Scott, Neurosciences Unit, Institute of Child Health, University College London, and Great Ormond Street Hospital for Children NHS Trust, London, UK

L Verhulst, M J Peters, Paediatric Intensive Care Unit, Great Ormond Street Hospital for Children NHS Trust, London, UK

\section{REFERENCES}

1 Leppik IE. Status epilepticus. Clin Ther 1985;7:272-8.

2 DeLorenzo RJ, Hauser WA, Towne AR, et al. A prospective, population-based epidemiologic study of status epilepticus in Richmond, Virginia. Neurology 1996;46:1029-35.

3 Lacroix J, Deal C, Gauthier M, et al. Admissions to a pediatric intensive care unit for status epilepticus: a 10-year experience. Crit Care Med 1994;22:827-32

4 Towne AR, Pellock JM, Ko D, et al. Determinants of mortality in status epilepticus. Epilepsia 1994;35:27-34.

5 Scholtes FB, Renier WO, Meinardi H. Status epilepticus in children. Seizure 1996:5:177-84.

6 Maytal J, Shinnar S, Moshe SL, et al. Low morbidity and mortality of status epilepticus in children. Pediatrics 1989;83:323-31.

7 Dunn DW. Status epilepticus in children: etiology, clinical features, and outcome. J Child Neurol 1988;3:167-73.

8 Knudsen FU. Rectal administration of diazepam in solution in the acute treatment of convulsions in infants and children. Arch Dis Child 1979;54:855-7.

9 Emergency Paediatrics Section of the Canadian Pediatric Society. Management of the paediatric patient with generalized convulsive status epilepticus in the emergency department. Paediatrics \& Child Health $1996 ; 1: 151-5$

10 The Advanced Life Support Group. Advanced Paediatric Life Support: The Practical Approach. 2nd ed. London: BMJ Publishing Group, 1997.

11 The Advanced Life Support Group. Advanced Paediatric Life Support: The Practical Approach. 3rd ed. London: BMJ Publishing Group, 2000.

12 Epilepsy Foundation of America's Working Group on Status Epilepticus. Treatment of convulsive status epilepticus. Recommendations of the Epilepsy Foundation of America's Working Group on Status Epilepticus. JAMA 1993:270:854-9.

13 Gastaut H. Classification of status epilepticus. Adv Neurol 1983;34:15-35.

14 Commission on Classification and Terminology of the International League Against Epilepsy. Proposal for revised classification of epilepsies and epileptic syndromes. Epilepsia 1989;30:389-99.

15 Hesdorffer DC, Logroscino G, Cascino G, et al. Incidence of status epilepticus in Rochester, Minnesota, 1965-1984. Neurology 1998;50:735-41.

16 Coeytaux A, Jallon P, Galobardes B, et al. Incidence of status epilepticus in French-speaking Switzerland: (EPISTAR). Neurology 2000;55:693-7.

17 Nelson KB, Ellenberg JH. Prognosis in children with febrile seizures. Pediatrics 1978;61:720-7.

18 Norris E, Marzouk O, Nunn A, et al. Respiratory depression in children receiving diazepam for acute seizures: a prospective study. Dev Med Child Neurol 1999:41:340-3

19 Stewart WA, Harrison R, Dooley JM. Respiratory depression in the acute management of seizures. Arch Dis Child 2002;87:225-6.

20 Appleton R, Choonara I, Martland T, et al. The treatment of convulsive status epilepticus in children. Arch Dis Child 2000;83:415-19.

21 Scott RC, Neville BG. Pharmacological management of convulsive status epilepticus in children. Dev Med Child Neurol 1999;41:207-10.

22 Lothman $\mathbf{E}$. The biochemical basis and pathophysiology of status epilepticus. Neurology 1990;40:13-23.

23 Scott RC, Besag FM, Neville BG. Buccal midazolam and rectal diazepam for treatment of prolonged seizures in childhood and adolescence: a randomised trial. Lancet 1999;353:623-6.

24 Scott RC, Besag FM, Boyd SG, et al. Buccal absorption of midazolam: pharmacokinetics and EEG pharmacodynamics. Epilepsia 1998;39:290-4.

25 O'Regan ME, Brown JK, Clarke M. Nasal rather than rectal benzodiazepines in the management of acute childhood seizures? Dev Med Child Neurol 1996;38: 1037-45. 